\title{
Using SAP R/3 To Teach Fixed Asset Accounting And Business Process Reporting
}

Joseph M. Ragan, (Email: jragan@sju.edu), Saint Joseph’s University

Gregory Giagnacova, (Email: gregory.giagnacova@sju.edu), Saint Joseph’s University

David Naab, (Email: david.naab@sju.edu), Saint Joseph’s University

\begin{abstract}
This paper describes a simulation model specifically for the Financial Accounting Information Systems course - an SAP enabled course for junior Accounting majors. Supporting and measuring the Supply Chain through technology is a key goal of Accounting and should therefore be reflected in an Accounting curriculum. It will assist students to learn both the benefits, and costs, involved with implementing ERP software. The purpose of this case is to present students with a set of business scenarios, and allow for the students to make educated and knowledgeable decisions using the SAP R/3 software. The scenarios will act as a simplified replication of the business environment; thus, they will provide the students with an integrated learning experience. Students make business decisions to ensure the profitability and cash flow of their respective product lines. While making these decisions, students participate in the application and analysis provided by IDES, the simulated company integrated into the SAP system. Eventually, they will need to justify the existence of their division by presenting profitability analysis. To provide a "learning-by-doing" experience, the scenarios will be used to demonstrate the reporting functionality within IDES. Today's global economy is putting a premium on the ability of students to evaluate a broad range of decisions in collaboration with adaptive supply chains. A critical component of the evolving accounting curriculum lies in the ability to extend students beyond the numbers to evaluate the effective and efficient delivery of these supply chains. This paper includes our Fixed Asset Explorer Scenario, as well as a Capital Budgeting Analysis using Microsoft Excel.
\end{abstract}

Keywords: Pedagogy, process integration, simulations, ERP, SAP

\section{INTRODUCTION}

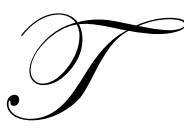

he purpose of this paper is to examine the method used to integrate the accounting curriculum with the use of SAP R/3 technology. In this paper, we will include the model of the course along with some course material.

The use of Enterprise Resource Planning systems in the business world is found in most global Fortune 500 firms which use some form of ERP, with SAP and ORACLE being the leaders. Nearly $73 \%$ of Fortune 500 companies employing ERP systems use SAP. Companies that choose to implement an ERP system are making a hefty investment, not just in money, but in time and training. The introduction of ERP into a company's business system greatly alters the accountant's duties. Automating the Accounting Information System means the accountant no longer has to perform the day-to-day book keeping procedures. Instead, the computer is able to handle these data-processing activities on a routine basis. As a result, accountants are becoming involved in the more dynamic functions of their organizations, for example aiding in management decision making and designing more effective business information systems to enable strategic analysis. 
With the rise of Sarbanes-Oxley, there has been a whole new field opened to accountants, which examines and tests controls of these ERP systems in accordance with the new legislation. Accountants are now performing broader duties, such as testing a system's effectiveness, as well as applying new business strategies and solutions with the aid of the ERP system. With these changes becoming mainstream in the world of business, it is critical for accountants to gain an understanding of the new path the SEC and Sarbanes-Oxley have provided.

The use of ERP systems in the accounting classroom helps to show students how a simple business transaction, such as a sales order, effects the organization as a whole. By performing transactions, the students become familiar with the structure of the organization, the effect the transaction has on the accounting records, and the use of this information to solve problems. By providing students with this advanced learning experience, students can now think more like upper management and understand the limitations and opportunities that an ERP system provides. It also enables students to gain some comfort over the system through monitoring its business functions, as well as providing detailed accounting reports with the operations they have simulated through the system.

\section{BACKGROUND AND PRIOR RESEARCH}

Albrecht and Sack (2000) paint a dismal portrait of the academic accounting profession as a discipline stuck in the past and exhibiting an unwillingness to change. They observed that technological innovation has rendered the gathering and reporting of information as an inexpensive process in today's environment. Accountants must be armed, they proposed, with new skills if they are to find a role in today's environment. They suggested that accounting educators should embrace the unfolding Internet revolution and include this experience as an integral part of the pedagogy of accounting education.

Accounting professionals also recognize this revolutionary change, and promote the implementation of higher technology for business processes. The AICPA (2000b) has made internet usage one of its top ten technologies for the start of the new century. When professionals were asked what skill other than financial expertise was most critical for success in the accounting discipline, the overwhelming choice was Internet technology (AICPA, 2000a). Educational organizations, such as the Federation of Schools of Accountancy (1999), have offered strong recommendations for specific actions that might be taken by today's universities in an effort to improve technology education. Greater reliance on the Internet is one of the cornerstones of such proposals.

The overall conclusion to be drawn from recent literature geared toward technological integration is that the current level of exposure that accounting students have to Internet-related technologies is too limited. Tuteja (2000) notes that software applications-like enterprise resource planning (ERP) technologies - may generate great risk to educators in an environment of limited resources. Stedman (1999) determined that as colleges and universities adopted ERP applications for their own organizational management uses, they found a "secret resource" for use in the classroom. In customizing this type of system for classroom applications, some educational institutions seem to have found a unique way to attract students back to the classroom. Becerra-Fernandez, Murphy, and Simon (2000) note that demand for trained enterprise resource planning professionals has motivated a number of universities to join alliances with ERP software vendors such as SAP. The primary vehicle such vendors have to make their product work in the educational marketplace is through the Internet. Kaveney (2000) confirms that Internet capabilities enabled his own institution (Syracuse University) to substantially enrich both the curriculum and pedagogy in its business programs.

A particularly interesting point raised in literature deals with the role of accounting as a business integrator. George and Asha (2002) see ERP as the perfect vehicle to teach the supply chain and since SAP is a monolithic Accounting Information System it serves the effort well to demonstrate integration through accounting. Volkoff notes (2003) that teachers are currently developing cases to give a concrete sense of what it means to configure and develop ERP based software. The benefits derived provide even the accounting students with a unique appreciation for the challenge of information delivery in the future. Chau and Chan (2002) see ERP as the perfect vehicle to teach continuous process improvement and enhance project decision making. Their paper further calls for a systematic implementation process incorporating the tools from ERP into the classroom. Draijer and Schenk (2004) 
state that a hands-on approach will motivate students; subsequently, this will increase their understanding of the business processes. Kirby (2002) notes that, ERP has essentially overcome all the implementation problems it originally experienced, and is now the vital engine by which key information is generated for the modern business. Roby, Ross, and Boudreau (2002) reports that schools are now attempting to teach integration with the use of ERP based technologies to enhance the placement of students and build stronger core skills and consulting capabilities within their students.

The issue for study, then, is how academic accountants, the educators of future professionals, should and should not use this ERP technology to educate. The first task was choosing which version of ERP to use. SAP R/3 was chosen because it has a formal University Alliance Program, of which Saint Joseph's University is a member. As a member, Saint Joseph's University receives the full ERP suite, which includes 12 major modules including forecasting, production planning, and material requirement planning areas. To date, St. Joseph's University has received over $\$ 100,000$ in grants to test the implementation of SAP in the classroom. "From and educational point of view SAP's R/3 is an ideal tool to illustrate business processes and process integration" (Draijer and Schenk 2004).

\section{SAP UNIVERSITY ALLIANCE PROGRAM}

The SAP University Alliance Program for the United States, Canada, Central and South America builds upon the best components of such a program originally developed for European institutions of higher education. It has been developed by SAP America to facilitate the use of their software package (and integrated business solutions concepts) in the formal education of undergraduate and graduate students throughout the Americas. The program has grown from a charter group of five members in 1997 to over 124 member institutions as of March 2005. The Haub School of Business is proud to be among the early schools granted admission in 1998.

Upon admission to the SAP America University Alliance Program, new members receive four significant and valuable items. First, a fully functional copy of the SAP R/3 software, or the right to time-share, with a major service provider is acquired. Second, they receive copies of all professional training materials utilized by SAP. Third, one hundred days of free training for faculty members at SAP professional training classes. The amount of training is dependent upon the level of involvement that a member institution desires. Fourth, they are given access to technical support from SAP. In addition, SAP is actively working with its member institutions to ensure cooperation and sharing of course materials among member institutions.

\section{CURRICULUM INNOVATIONS}

Pedagogical revisions to the undergraduate curriculum in Accounting at the Haub School of Business encompass two broad categories. First, a newly created three-course sequence encompassing Intermediate and Advanced Accounting has been prepared. These courses are newly titled as Financial Accounting Information Systems I, II, and III. The three-course sequence focus is a single continuous learning experience traversing sophomore to junior year. Each course will progressively build upon and expand the knowledge base acquired in the prior course. This knowledge base will include topical content in Accounting and application ability within SAP $\mathrm{R} / 3$. Second, another group of courses taught in the sophomore year incorporates subject matter inherent to cost and managerial accounting. These courses are titled Managerial Accounting Information Systems I an II. The SAP exposure afforded students within these course sequences will provide hands on experiences in a team-oriented format within a business case context. It is envisioned that a single business case will be used throughout these five courses.

\section{Collaborative Learning Model (STAR Scholars)}

A unique feature of the course pedagogy is the utilization of STAR Scholars to assist in development and delivery of various SAP scenarios. These scholars are chosen through a highly selective process and specially trained to deal with these application scenarios. To date, there are some forty STAR Scholars comprised mostly of juniors and senior undergraduate majors. These students are compensated for the work done in class and are 
provided with enrichment activities, such as field visits and special speakers, helping them to understand the essentiality of implementation of state of the art software. They often participate in research-based projects designed and developed by faculty. In addition, STAR Scholars involve themselves in a series of special activities under the direction of a Faculty mentor. Developing scenarios of various computer applications involving Enterprise Resource Planning software and SAP are included. In addition, seminars with entrepreneurs and technology leaders are held to provide opportunities to interact on a personal and informal level with business leaders. Sponsored participation in special events with alumni working in technology and consulting fields is also a component. These students assist in classroom delivery and continue to service the course by maintaining a help desk for students.

STAR Scholars are also responsible for providing the instructor with valuable feedback from the students regarding how the ERP rollout is progressing. By interacting with the students in the classroom, the STAR Scholars are able to determine general strengths and weaknesses of the class, and where extra emphasis or explanation needs to be placed in order to enhance the learning experience. The STAR Scholars take their observations and regularly meet with the instructor to find ways to add value to the students' experience through unique and innovative projects that engage the students and challenge their knowledge of the SAP system. Working with STAR Scholars often creates a comfort zone for the student enabling them to build confidence within the system and apply textbook accounting concepts to their analytical simulations. STAR Scholars are also regularly available outside of classroom hours to provide additional support through the Student Help Desk that they have established and operate independently from the instructor. The Student Help Desk is open to all students enrolled in these courses, who would like additional help in going through assignments or reviewing previous class work.

\section{PHASES OF THE CURRICULUM ROLLOUT}

The courses are three-credit courses required for all accounting majors, typically in the sophomore and junior years. SJU requires all students to have laptops allowing for the SAP rollout to take place outside the classroom. While an SAP-enabled course could ideally be taught in a computer laboratory, the instructor would lose the capability to give assignments outside the classroom. For example, by requiring individual laptops for each student, they are able to perform business operations for the first time in classroom, and then have the capability reperform it outside of class, on their own, and for credit. These outside of the classroom assignments are the means by which the learning assessment takes place. A typical class consists of 24 students and is taught over a fourteen week semester. The university is a member of the SAP Alliance. As a member of the University Alliance, SJU is given access to SAP R/3 in real time through the University of Wisconsin at Milwaukee. The objectives of the curriculum rollout were agreed upon by the department faculty in advance.

\section{Phase I - Purchasing Phase}

The objectives established for this phase were to better understand core business processes and their linkage to accounting. The purpose of bringing SAP into the classroom further demonstrates how the roles of accountants have changed with technology. Today, accountants interpret business situations and use information to make decisions; they no longer simply add and subtract. It was found that using the concept of scenarios was the most ideal way to bring business situations using SAP R/3 into the classroom and have the students enter the information, master data and transactions, then see how the system uses the information, and finally use the information to make decisions for the business.

Scenarios are written in the form of scripts and tested by the STAR Scholar Team prior to their use in class. Not only do the scripts contain the procedures to follow within the system, but they also contain important accounting definitions and processes, which are referenced to textbook pages for further reading. By integrating key points from the textbook into the scripts, students find it easier to apply the accounting to the ERP system as they move through the different processes. The typical scenario takes them through the following steps; master file $\rightarrow$ process $\rightarrow$ report $\rightarrow$ analyze. First they create a master file; in the scenario in Appendix I, a Fixed Asset and Vendor master are created. The students are usually asked to select a name that they will be able to easily identify and remember (such as Vandalay's Mercedes). Following the creation of master files, the application process is 
performed. Students have created a vendor and a fixed asset; the application process allows them to purchase their asset. During this stage, students develop recognition of the information integrated between the master files and the application process in the simulated environment IDES cerates. This enables the students to better analyze the reports generated in the phases that follow. The last step is analyzing the process in terms of the effects it had on the business. For the Fixed Asset Scenario attached in Appendix I, we use the SAP Fixed Asset Explorer, as well as the journal entries recorded by the purchase of their asset.

Giving the students a script that has been written out and tested gives them a path to follow so they do not get lost in the overwhelming nature of SAP. Through the innovation of this course, the instructor is able to choose a student at random before each class to lead each scenario on the over-head monitor in the classroom. This lead student provides visual guidance, with the support of the STAR Scholars, to the rest of the class. After completing the scenario as it is written, students feel more comfortable working in the modular area in which the scenario operates. There is no such thing as an SAP expert, but there are experts in certain modules. This course was designed to make students feel comfortable when operating within the system, not to create experts.

It is essential for students to understand the relationship between the concept coverage within the text and the applications within SAP. A very simple overview of SAP navigation is completed in this process. The students leave with a scavenger hunt assignment using SAP navigation. Students are also introduced to the faculty website and the blackboard location for course documents and assignments. These topics primarily include financial statement reporting and assets. As each topic is reviewed, assignments are handed out for completion by the students, and subsequently graded. Within this first course there is an attempt to provide at least $20 \%$ of the course grade to SAP applications. It is particularly important that the students gain an appreciation of the fact that this is just the first course in which they will use SAP to enhance their study of accounting. In effect, SAP becomes the integrating factor for the entire accounting curriculum. An attitude assessment conducted at this point indicates that students appreciate the more active learning approach necessitated by more hands-on computer use. In addition, students realize that the computer is doing the mechanical calculations and it is their job to manage the process flow and determine where the information is going.

\section{Phase II- Asset Reporting Phase}

The major topics in a typical Cost Course emphasize volume cost-profit behavior analysis, capital budgeting, and responsibility. The objective of this phase is to improve information problem solving skills using SAP reports. The scenarios written in these areas give students the opportunity to create a budget around a cost center and, as a team, measure performance and determine direction. This is done through team-based case simulations (as they now appear on the CPA exam) where students are asked to advise a client what to do regarding product cost overruns and low profitability. The SAP Asset Explorer provides a dynamic report that allows the analysis of multiple depreciation and costing methods - these range from straight line to Federal MACRS. The functionality of this report is extraordinary. Because the students purchase a car as their fixed asset, a depreciation lifetime of five years is given by default; however, the report allows the user to simulate a longer or shorter useful life. SAP R/3 is known to be the most fully integrated ERP system available today. The material master, vendor master, general ledger account master, cost center, purchase order, and all journal entries involved with the process are linked through the Asset Explorer. This integration gives students a macro view of the process and allows for better analysis in further scenarios.

A good way to create interest for the students is to use the email function within the system. This is done by emailing a question from our hypothetical employee, such as a CEO, CFO, etc., asking a question pertaining to the scenario. After the scenario is performed the students respond to the question which forces them to explain the task they performed and how it affected the business. Each student's response will contain an attached report, which will give the instructor enough information to give the student credit for the assignment. 


\section{Phase III- Analysis Phase}

Students are provided a series of application problem scenarios where they have to provide information reports on the performance of a series of fixed assets. In this phase the role of technology as a cost controller is introduced to students. Excel is utilized to develop the student's financial modeling skills. An Excel demonstration is provided in Appendix II. From the SAP Asset Explorer, Students are asked to export the straight line depreciation breakdown to Microsoft Excel and perform a capital budgeting analysis regarding their asset. Once exported, the spreadsheet is formatted and assumptions are stated (i.e. tax rate, revenue generation, etc.) Students create a financial model to determine after-tax income and perform a Net Present Value evaluation. Following the evaluation, students provide a written analysis of the NPV (via e-mail) to our hypothetical employee to justify the purchase of their fixed asset.

Each case is graded competitively based on project presentation correct solution and clarity of information. Post surveys indicate real satisfaction with the group work and desire to make the course even more case oriented. Given the case orientation, grades tend to be higher than a normal advanced cost accounting course. The ultimate goal here is to make decisions that lead directly to benefits. Student assessment surveys indicate students have a renewed appreciation on how accounting information affects management decision making and see the role nonfinancial metrics play in shaping the performance and direction of the firm. Significant attention must be paid to the grading process in this phase. Students are not only graded in a normal test mode, but also are assessed points based on innovative and creative solutions communicated succinctly and efficiently to managers. A team presentation of project outcomes helps bring closure to the course and leads to conclusions that are often contingent and uncertain. This unstructured analysis often frustrates students.

\section{EVALUATING STUDENT PERFORMANCE}

Points are assigned to each student project for both individual assignments and the group presentation. To determine whether or not the students have completed the individual assignments, inside or outside of the classroom, the SAP R/3 system is used. There are two methods used to help keep track of what the students have completed. First, the students are given control numbers that are used throughout the semester. These numbers are used when creating their master files so that they are easier to find within the system. Second, the students have used their own names when creating master files.

The system has controls built in that enable the ability to track what user names have completed assignments. There are two ways to do this. The students can send an email using the system, and attach a transaction file number or master file number, so that it is then possible to look up those individual files in the system. Or, a list could be brought up that will show all the files created by the students. For individual projects, the latter is found to be more efficient. For example, if the students' assignment is to create a cash account, a balance sheet account can be accessed, that has all the cash accounts listed, so it can be determined which students completed the assignment correctly and which did not. Because control numbers are used, and the accounts are listed in sequential order, it is easy to see which students failed to complete the assignment.

In addition to the project assignment questions, referencing and using SAP as an example to demonstrate text book material are also used on exams. Therefore, students must not only understand the textbook concepts, but also be able to identify examples using their experience with SAP to determine how this is useful or necessary for a system.

\section{LESSONS LEARNED}

What does this experience suggest regarding the future of accounting education? A more holistic approach to teaching professional accountants suggests that a framework exists over a series of courses. Topics can be divided within that framework, but must use a common theme or case. In this case, the common theme was SAP and the case was the IDES training database provided by the University Alliance. Would other topics and themes 
work? Active learning with technology is a major positive and has the ability to bring outside resources and alumni into the classroom to help more advanced units.

Innovation comes at a price. The need to build incentives for faculty is particularly important. The role of the STAR Scholars can not be understated. Without their assistance, hands-on activities in class and help-desk support would not be possible. The possibility of a graduate level rollout using SAP and its more advanced modules, such as Customer Relationship Management and Strategic Enterprise Management, is under consideration. It will be used as the topic of a follow-up study.

\section{CONCLUSION}

Generally, students were enthusiastic when approaching the SAP R/3 application scenarios in each of the phases. Because of the current shift from legacy systems to ERP throughout the real world business environment, the students exhibited heightened interest regarding the study of the leading ERP package, SAP. Implementing in phases over a series of courses offered many benefits - amplified participation, learning through repetition, etc. opposed to the use of a single course driven entirely by the study of ERP. This phased approach also allows the instructor to make key references to textbook topics as they are covered in class, rather than learning the accounting concepts in one course and the ERP system in another. In short, literature suggests accounting education must change dramatically to keep up with the needs of business. Saint Joseph's University attempts this by spending less time in comprehensive coverage and memorization of rules, and more time integrating a learning-by-doing environment through dynamic exercises employing cutting edge technology and real world business scenarios.

\section{REFERENCES}

1. AICPA (2000a). AICPA Core Competency Framework for Entry into the Accounting Profession, http://www.aicpa.org/edu/func.htm.

2. AICPA Top Ten Technologies Task Force (2000b). The AICPA Top Ten Technologies for 2000, http://www.toptentechs.com.

3. Albrecht, W. Steve and Robert J. Sack. Accounting Education: Charting the Course Through a Perilous Future. Sarasota, FL: American Accounting Association, 2000.

4. Becerra-Fernandez, Irma, Kenneth E. Murphy, and Steven J. Simon. Integrating ERP in the Business School Curriculum, Communications of the ACM, April 2000, pp. 39-41.

5. Draijer, Casper and Schenk, Dirk-Jan. Best Practices of Business Simulation with SAP R/3. Journal of Information Systems Education 15.3 (2004): 261-265.

6. Chau, K Y, and Chan, S F. Implementing ERP through continuous improvement. International Journal of Manufacturing Technology and Management. Geneva: 2002. Vol. 4, Iss. 6; p. 465

7. Federation of Schools of Accountancy (1999). Recommendations for the Design of Empirical Studies Examining Curricular Efforts to Develop Student Critical Thinking Skills, http://www.thefsa.org/publications/studies.htm.

8. George Joseph, and Asha George. ERP, learning communities, and curriculum integration Journal of Information Systems Education, 2002, Vol. 13, Iss 1; pg. 51, 8 pgs

9. Kaveney, Michael. Syracuse University to Have New ERP Lab, Business Journal 14 (2/18/00), p. 27.

10. Kirby, Horton. ERP; A bearing on success. Works Management. Nov 2002. Vol. 55, Iss. 11; p. 8

11. Robey, Daniel, Ross, Jeanna W., Boudreau, Marie-Claude. Learning to implement enterprise systems: An exploratory study of the dialectics of change. Journal of Management Information Systems. Armonk: Summer 2002. Vol. 19, Iss. 1; p. 17

12. Stedman, Craig. College ERP Success: May Take Custom Fit, Computerworld 33 (11/29/99), p. 12.

13. Tuteja, Akhilesh. Enterprise Resource Planning: It Can be Risky, May 1, 2000, http://www.itaudit.org.

14. Volkoff, Olga. Configuring an ERP system: Introducing best practices or hampering flexibility? Journal of Information Systems Education. West Lafayette: Fall 2003. Vol. 14, Iss. 3; p. 319 


\section{APPENDIX I: FIXED ASSET MANAGEMENT}

\section{Objectives}

1. Create an Asset on the books

2. Create a Purchase Order

3. Post the Goods Receipt

4. Posting the Invoice Receipt

5. Displaying the Asset in Asset Explorer

\section{WHAT ARE FIXED ASSETS?}

(Kieso pp. 470-471, 1205-1206)

Fixed assets are generally referred to as the property, plant, and equipment that are used in business operations and are not for resale. Usually they are the largest financial investments requiring the organization to have sufficient internal controls. They are also long-term in nature and are subject to depreciation. The process of acquiring fixed assets, which is described in this script, is considered an investing activity on the statement of cash flows.

\section{Objective 1) Create an Asset on the books}

Accounting $\rightarrow$ Financial Accounting $\rightarrow$ Fixed Assets $\rightarrow$ Asset $\rightarrow$ Create $\rightarrow$ Asset

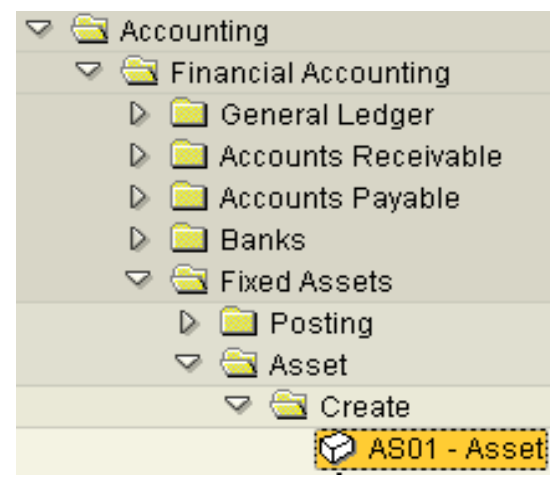

a) Enter the following:

\begin{tabular}{|c|c|}
\hline Field Name & Input \\
\hline Asset Class & 3100 \\
\hline Company code & 3000 \\
\hline Number of similar assets & 1 \\
\hline
\end{tabular}

\begin{tabular}{|l|l|}
\hline Asset class & 3100 \\
\hline Company code & 3000 \\
\hline Number of similar assets & 1 \\
\hline
\end{tabular}

The asset class identifies the type of asset being purchased. For example 3100, the class we are using identifies the asset as a vehicle. Other examples of asset classes are buildings, computers, real estate, and machines. 
Enter

\begin{tabular}{|l|l|}
\hline Field Name & Input \\
\hline Description & $\begin{array}{l}\text { Personalize your asset, making sure your name is a part of } \\
\text { the description }\end{array}$ \\
\hline
\end{tabular}

\begin{tabular}{|l|l|}
\hline General Time-dependent Allocatior \\
\hline General data \\
\hline Description & Porsche for Me \\
\hline
\end{tabular}

Choose the Time-dependent tab.

b) Enter the following:

\begin{tabular}{|c|c|}
\hline Field Name & Input \\
\hline Business area & 9900 \\
\hline Cost center & 4120 \\
\hline Plant & 3000 \\
\hline
\end{tabular}

\begin{tabular}{l}
\hline General \\
\hline
\end{tabular}

The cost center is the unit within the organization that is going to incur the cost of the asset. Cost centers are responsible for managing costs and staying within the limits of the budget set for them by management. Variances that compare actual costs to budgeted costs are one way of evaluating the performance of a cost center.

Save

Write down the asset number that you created; it will appear at the bottom left hand corner.

Return to Standard Menu 


\section{Objective 2) Create a Purchase Order}

Logistics $\rightarrow$ Materials Management $\rightarrow$ Purchasing $\rightarrow$ Purchase Order $\rightarrow$ Create $\rightarrow$ Vendor/Supplying Plant Known

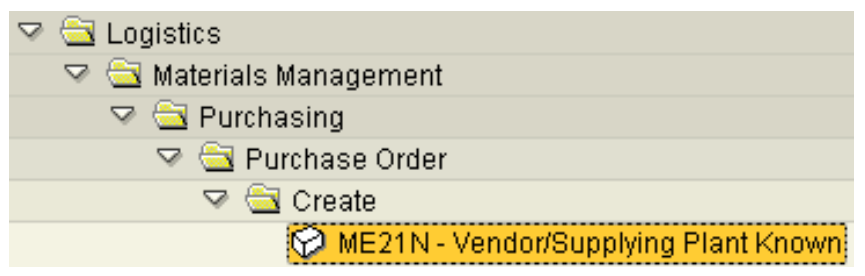

a) Enter the following:

\begin{tabular}{|c|c|}
\hline Field Name & Input \\
\hline Vendor & 3000 \\
\hline
\end{tabular}

In the Header section, click the Org. data tab (this tab might default)

\begin{tabular}{|c|c|}
\hline Field Name & Input \\
\hline Purchasing org. & 3000 \\
\hline Purch. group & 020 \\
\hline Company code & 3000 \\
\hline
\end{tabular}

If purchasing group does not show up at first, type in the information in the next step. Once you hit enter after the next step, purchasing group will appear, and you can type in the given input value. After you type that in, hit enter again.

In the Item Overview section, enter the following data in the corresponding fields:

\begin{tabular}{|c|c|}
\hline Field Name & Input \\
\hline A & A \\
\hline Short text & Same description used in the first objective \\
\hline PO Quantity & PC \\
\hline OU & Four weeks from today \\
\hline Delivery date & 80000 \\
\hline Net price & USD \\
\hline Currency & 012 \\
\hline Material group & 3000 \\
\hline Plant & 0001 \\
\hline Storage location & \\
\hline
\end{tabular}

*Helpful hint: Make a note of your short text here:

You might need to refer back to it later on.

You will have to scroll over to find Material group, Plant, and Storage location. 


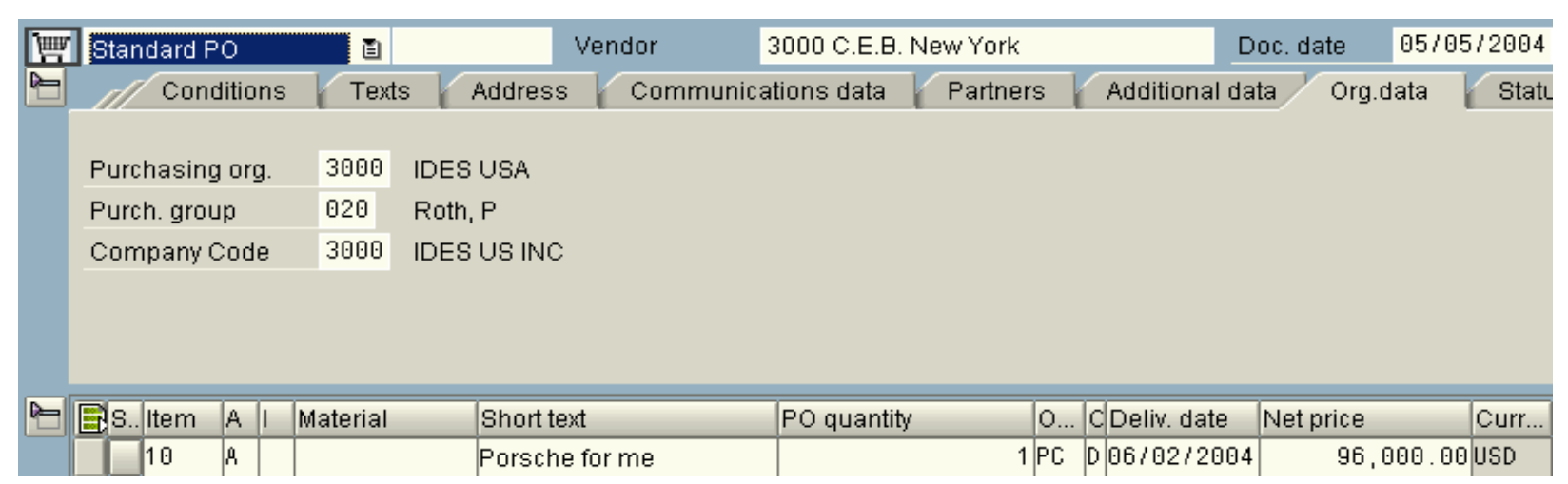

Enter

b) In the Items Detail section, enter the following data in the Account assignment tab.

\begin{tabular}{|c|c|}
\hline Field Name & Input \\
\hline Asset & Your asset number \\
\hline
\end{tabular}

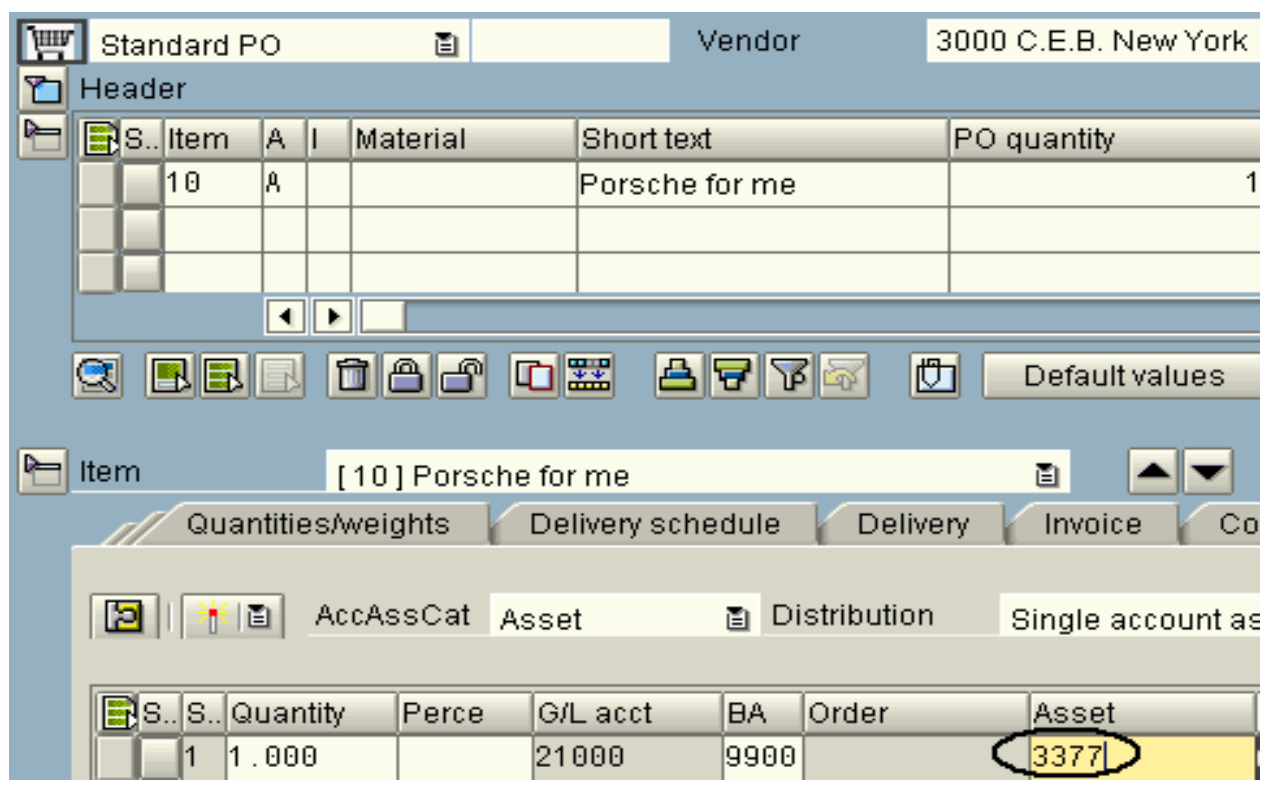

밈 Save

Write down the PO \#:

Return to Standard Menu (A) 


\section{Objective 3) Post the Goods Receipt}

Logistics $\rightarrow$ Materials Management $\rightarrow$ Inventory Management $\rightarrow$ Goods Movement $\rightarrow$ Goods Movement

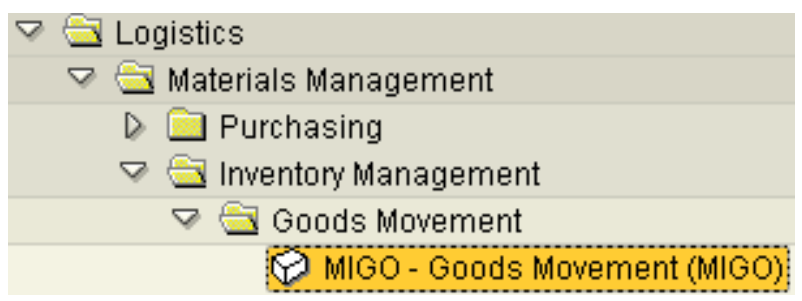

a) Enter the following:

\begin{tabular}{|c|c|}
\hline Field Name & Input \\
\hline PO number & Enter your PO number \\
Delivery Note & Good Condition \\
\hline
\end{tabular}

Enter

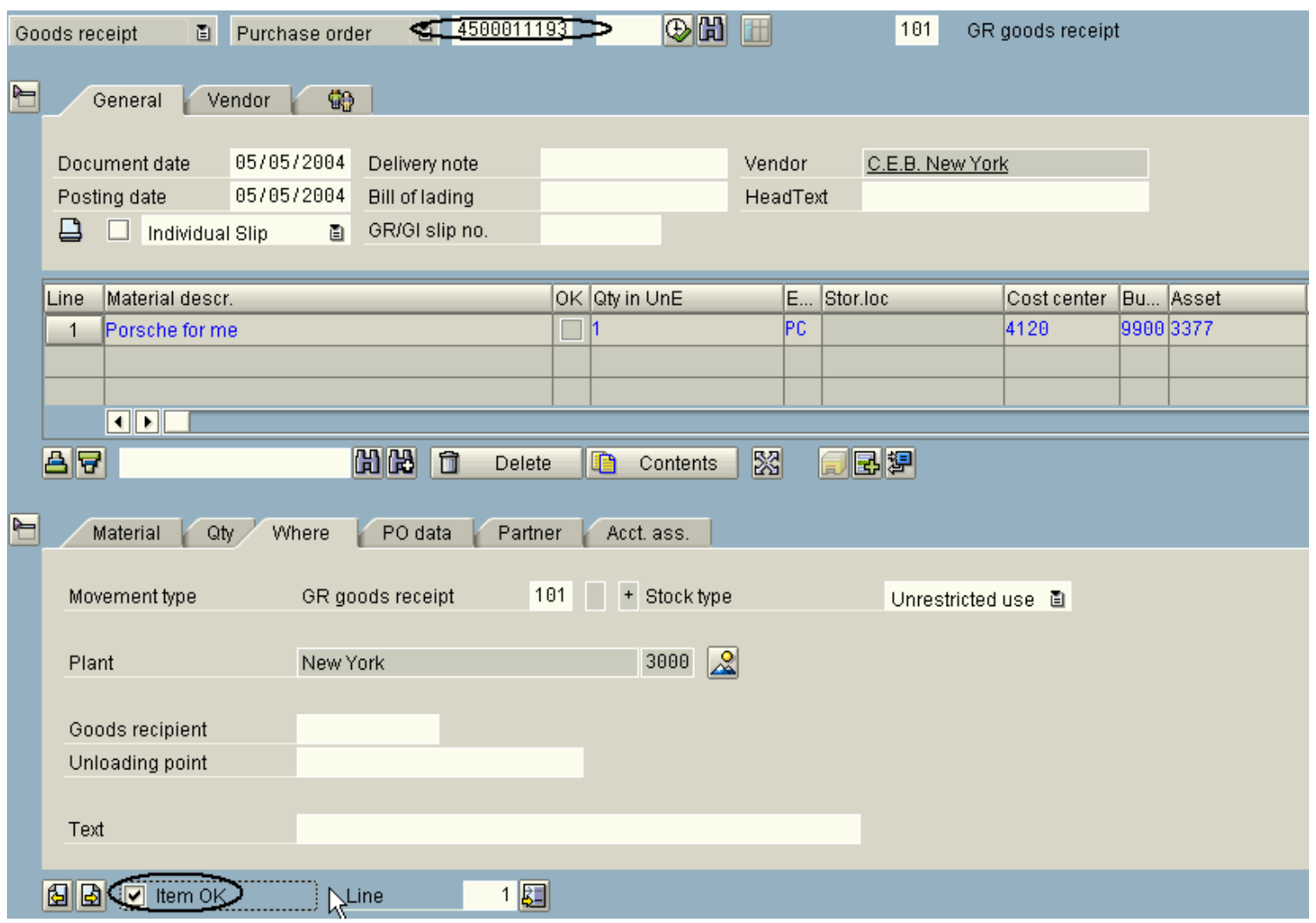

Check the box at the bottom of the screen that says Item OK.

밈 Save

Write down the material document number given: 


\section{Objective 4) Post the Invoice Receipt}

Logistics $\rightarrow$ Materials Management $\rightarrow$ Logistics Invoice Verification $\rightarrow$ Document Entry $\rightarrow$ Enter Invoice

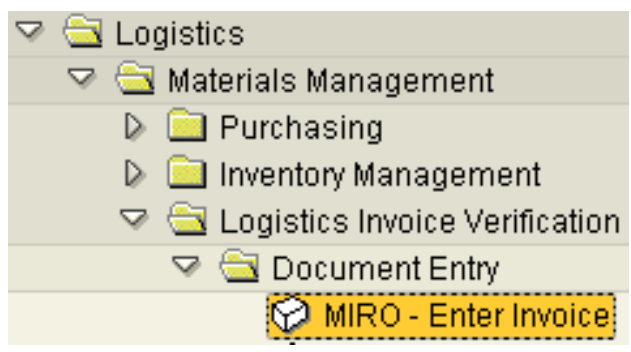

a) Enter the following:

\begin{tabular}{|c|c|}
\hline Field Name & Input \\
\hline Invoice date & Today's date \\
\hline Purchase order / scheduling agreement & Your PO number \\
\hline
\end{tabular}

Enter

\begin{tabular}{|c|c|}
\hline Field Name & Input \\
\hline Tax code & IO (in two places) \\
\hline Amount & 80000 \\
\hline
\end{tabular}

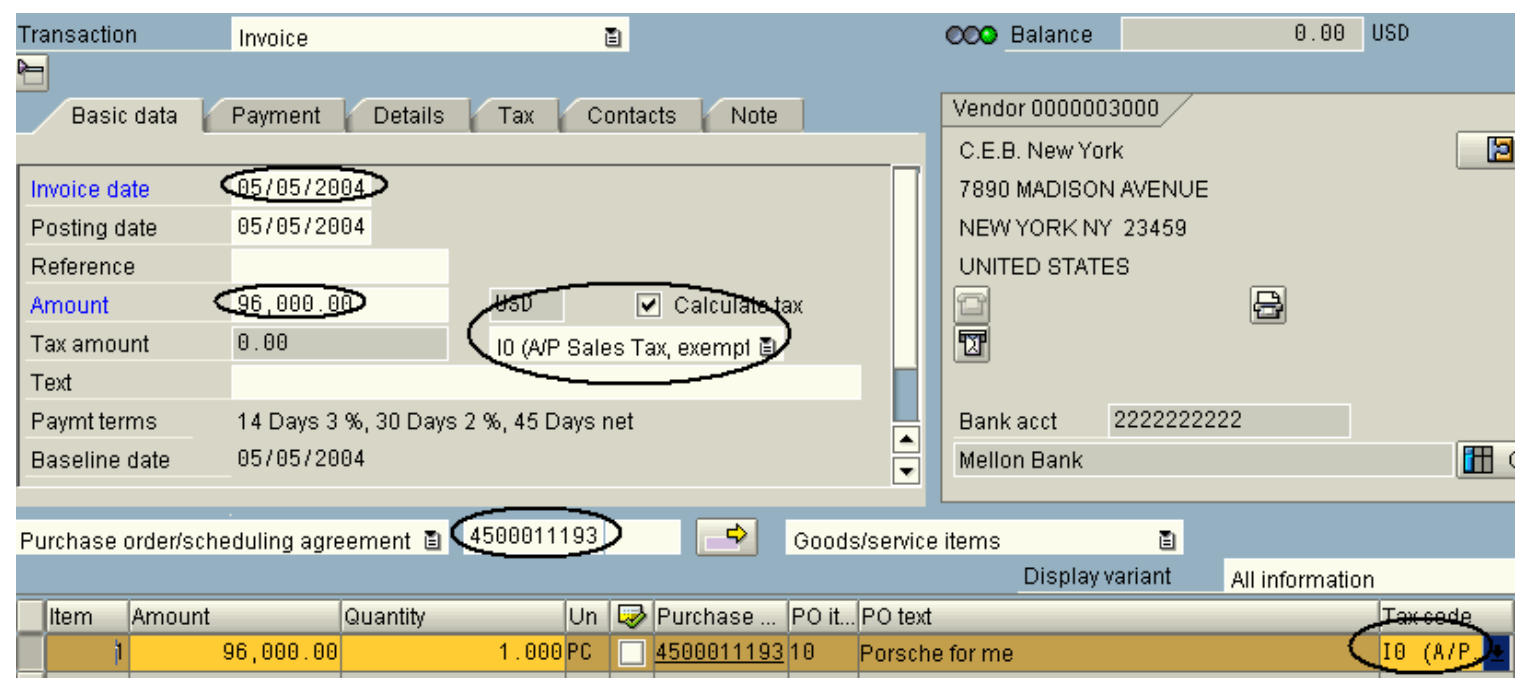

Save

Return to Standard Menu (S) 


\section{WHAT IS POGRI?}

(Hall Chapter 5)

Objectives 2, 3, and 4 perform the process of POGRI: purchase order, goods receipt, and supplier's invoice. Within the expenditure cycle, the purchase order is the document that includes the date ordered, date needed, vendor and vendor number, purchasing organization and group, description of material ordered, quantity ordered, and the purchase price and terms. To record the goods received, SAP uses the suspense account called "Goods Received/Invoice Received." When the assets are received, the asset is debited and the GR/IR account is credited. Then once the supplier's invoice is received, the GR/IR account is debited and the accounts payable account is credited, which records the liability. When purchasing assets, a good system of internal control will verify that what was ordered was received and what was received was billed for.

\section{Objective 5) Display the Asset in Asset Explorer}

\section{WHAT IS ASSET EXPLORER?}

The asset explorer feature within SAP is an asset management tool that displays multiple methods of depreciation. In addition, the asset explorer also fully integrates documents such as the purchase order, the vendor master, the cost center, and the journal entries to record goods receipt and invoice receipt. Asset explorer also offers a number of graphs, charts, and simulations to help aid in decision making. It is also possible to export depreciation tables to excel for further analysis.

Accounting $\rightarrow$ Financial Accounting $\rightarrow$ Fixed Assets $\rightarrow$ Asset $\rightarrow$ Asset Explorer

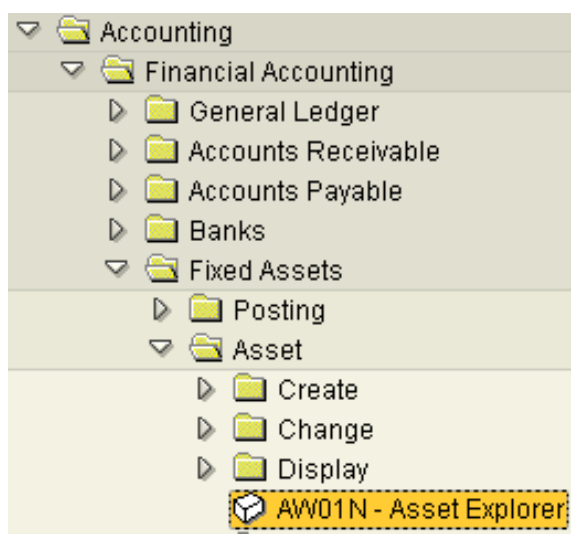

a) Enter the following:

\begin{tabular}{|c|c|}
\hline Field Name & Input \\
\hline Asset & Your asset number (should default) \\
\hline
\end{tabular}

Enter

There are many different features in the asset explorer. Here are some screen shots with explanations. 


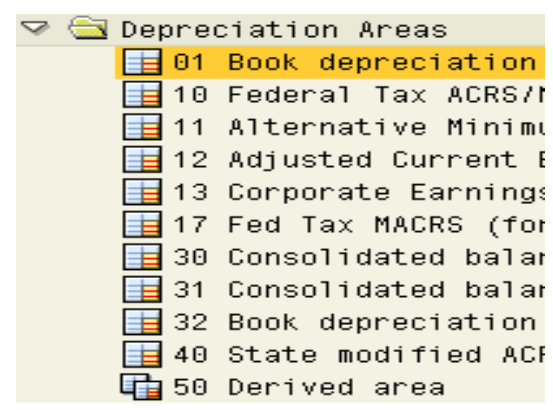

This portion of the screen demonstrates different types of depreciation. Clicking on each one will change the calculations on the screen because different depreciation expenses are used for each type.

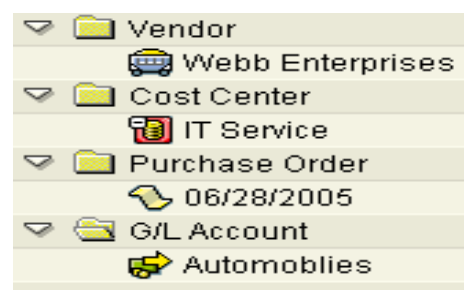

This screen includes all the objects associated with the asset: The vendor the asset was purchased from, the cost center the asset is assigned to, the purchase order used to order the asset, and the G/L account the asset is associated with in the books.

Company Code
Asset

The comparisons tab shows how the depreciation is expensed over the next five years. Because this is a vehicle, it has a five year useful life under GAAP. This is the book depreciation, also known as straight line depreciation. Notice only $\$ 12,800$ and $\$ 6,400$ are taken in 2004 and 2009 respectively. This is because the asset was purchased in the month of May.

$\underline{\text { Return to Standard Menu }}$ 


\section{Appendix II: Capital Budgeting Analysis}

Students are asked to export the Asset Explorer Report showing the Straight-Line Depreciation method. This is how the spreadsheet looks when it is initially exported:

$\begin{array}{lrrrr}\text { Fiscal year } & \text { APC transactions } & \text { Acquisition value } & \text { Ordinary deprec. } & \text { Net book value Crcy } \\ <2006 & 0.00 & 0.00 & 0.00 & 0.00 \text { USD } \\ 2006 & 80,000.00 & 80,000.00 & -13,334.00 & 66,666.00 \text { USD } \\ 2007 & 0.00 & 80,000.00 & -16,000.00 & 50,666.00 \text { USD } \\ 2008 & 0.00 & 80,000.00 & -16,000.00 & 34,666.00 \text { USD } \\ 2009 & 0.00 & 80,000.00 & -16,000.00 & 18,666.00 \text { USD } \\ 2010 & 0.00 & 80,000.00 & -16,000.00 & 2,666.00 \text { USD } \\ 2011 & 0.00 & 80,000.00 & -2,666.00 & 0.00 \text { USD }\end{array}$

After reformatting the initial export, students enter the assumptions regarding Initial Investment, Cash Flow per Year, Tax Rate, and the Discount Rate. Taxable Income takes the annual cash flow and subtracts the depreciation. Finally, tax expense is taken out of the annual cash flow to calculate the Net Cash Flow after Tax. From this information, the student creates a Net Present Value function to determine the profitability of their asset.

\begin{tabular}{lr}
\hline Fiscal year & Ordinary deprec. \\
$<2006$ & 0.00 \\
2006 & $-12,667.00$ \\
2007 & $-16,000.00$ \\
2008 & $-16,000.00$ \\
2009 & $-16,000.00$ \\
2010 & $-16,000.00$ \\
2011 & $-3,333.00$ \\
& \\
Assumptions & \\
Initial investment & 80,000 \\
Cash flow per year & 30,000 \\
Tax Rate & $15 \%$ \\
Discount Rate & $12 \%$ \\
& \\
NPV & $\$ 113,299.26$ \\
NPV after initial investmer & $\$ 33,299.26$
\end{tabular}

Below is the capital budgeting spreadsheet in "Audit Mode." Each cell is appropriately linked so that assumptions can be changed to reflect different projected cash flows, tax rates, and discount rates. By developing Excel modeling skills, students will be better equipped to take on such challenges on the job. 


\begin{tabular}{lllllll} 
Fiscal year & Ordinary deprec. & \multicolumn{2}{l}{ Net book value Crcy } & Taxable Income Tax Expense Net CF after tax \\
$<2006$ & 0 & 0 & USD & & & \\
2006 & -12667 & 67333 & USD & $=\$ B \$ 12+B 3$ & $=F 3^{*} \$ B \$ 13$ & $=\$ B \$ 12-G 3$ \\
2007 & -16000 & 51333 & USD & $=\$ B \$ 12+B 4$ & $=F 4 * \$ B \$ 13$ & $=\$ B \$ 12-G 4$ \\
2008 & -16000 & 35333 & USD & $=\$ B \$ 12+B 5$ & $=F 5 * \$ B \$ 13$ & $=\$ B \$ 12-G 5$ \\
2009 & -16000 & 19333 & USD & $=\$ B \$ 12+B 6$ & $=F 6^{*} \$ B \$ 13$ & $=\$ B \$ 12-G 6$ \\
2010 & -16000 & 3333 & USD & $=\$ B \$ 12+B 7$ & $=F 7^{*} \$ B \$ 13$ & $=\$ B \$ 12-G 7$ \\
2011 & -3333 & 0 & USD & $=\$ B \$ 12+B 8$ & $=F 8^{*} \$ B \$ 13$ & $=\$ B \$ 12-G 8$
\end{tabular}

Assumptions

Initial investment $\quad 80000$

Cash flow per year $\quad 30000$

Tax Rate $\quad 0.15$

Discount Rate $\quad 0.12$

NPV $\quad=N P V(B 14, H 3: H 8)$

NPV after initial investment $=B 16-B 11$

After the student completes the capital budgeting model, he or she sends an e-mail to the CEO of IDES, Art Vandalay. This a typical e-mail from a student justifying the purchase of their asset.

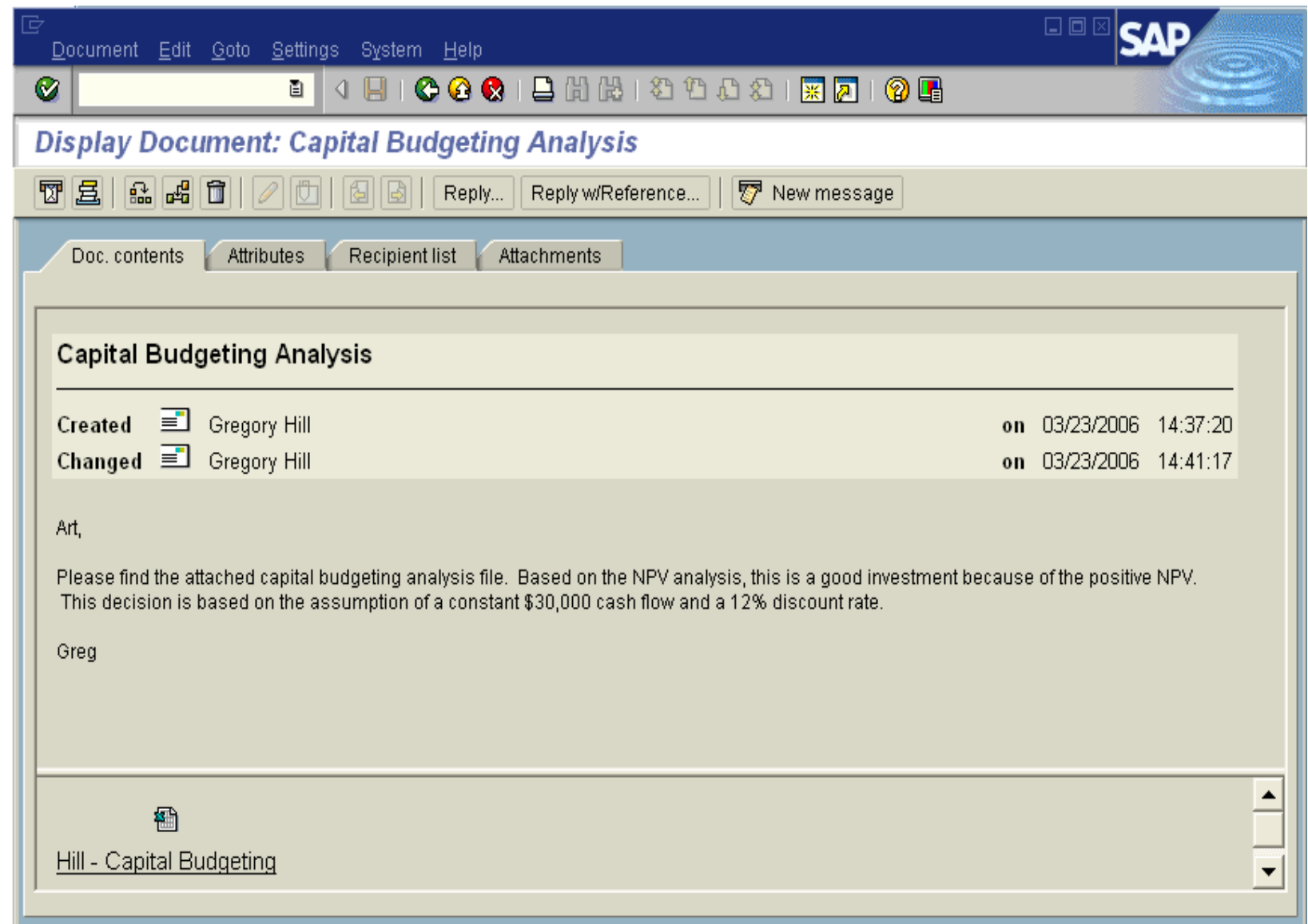




\section{NOTES}

